\title{
Do loss to follow-up and death rates from ART care vary across primary health care facilities and hospitals in south Ethiopia? A retrospective follow-up study
}

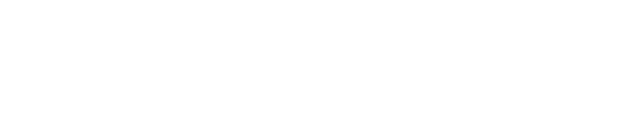

\section{Wondu Teshome' \\ Mehretu Belayneh' \\ Mathewos Moges' \\ Emebet Mekonnen ${ }^{2}$ \\ Misganu Endrias ${ }^{2}$ \\ Sinafiksh Ayele ${ }^{2}$ \\ Tebeje Misganaw ${ }^{2}$ \\ Mekonnen Shiferaw ${ }^{2}$ \\ Tigist Tesema ${ }^{2}$}

'School of Public and Environmental Health, Hawassa University, ${ }^{2}$ Health Research and Technology Transfer Support Process, Southern Nations Nationalities and Peoples' Regional Health Bureau, Hawassa, Ethiopia
Correspondence: Wondu Teshome School of Public and Environmental Health, Hawassa University, PO Box 1560, Hawassa, Ethiopia Email wondu_teshome@yahoo.com
Background: Decentralization and task shifting has significantly improved access to antiretroviral therapy (ART). Many studies conducted to determine the attrition rate in Ethiopia have not compared attrition rates between hospitals and health centers in a relatively recent cohort of patients. This study compared death and loss to follow-up (LTFU) rates among ART patients in hospitals and health centers in south Ethiopia.

Methods: Data routinely collected from patients aged older than 15 years who started ART between July 2011 and August 2012 in 20 selected health facilities (12 being hospitals) were analyzed. The outcomes of interest were LTFU and death. The data were entered, cleaned, and analyzed using Statistical Package for the Social Sciences version 20.0 and Stata version 12.0. Competing-risk regression models were used.

Results: The service years of the facilities were similar (median 8 and 7.5 for hospitals and health centers, respectively). The mean patient age was $33.7 \pm 9.6$ years. The median baseline CD 4 count was 179 (interquartile range 93-263) cells $/ \mathrm{mm}^{3}$. A total of 2,356 person-years of observation were made with a median follow-up duration of 28 (interquartile range $22-31$ ) months; $24.6 \%$ were either dead or LTFU, resulting in a retention rate of $75.4 \%$. The death rates were 3.0 and 1.5 and the LTFU rate were 9.0 and 10.9 per 100 person-years of observation in health centers and hospitals, respectively. The competing-risk regression model showed that the gap between testing and initiation of ART, body mass index, World Health Organization clinical stage, isoniazid prophylaxis, age, facility type, and educational status were independently associated with LTFU. Moreover, baseline tuberculous disease, poor functional status, and follow-up at a health center were associated with an elevated probability of death.

Conclusion: We observed a higher death rate and a lower LTFU rate in health centers than in hospitals. Most of the associated variables were also previously documented. Higher LTFU was noticed for patients with a smaller gap between testing and initiation of treatment.

Keywords: antiretroviral therapy, primary care, loss to follow-up, death rates, Ethiopia

\section{Introduction}

The World Health Organization (WHO) estimates that approximately 35.0 million people were living with human immunodeficiency virus (HIV) at the end of 2013, with 2.1 million people becoming newly infected with HIV in 2013 globally. In 2013, 12.9 million people living with HIV were receiving antiretroviral therapy (ART) globally, of which 11.7 million were receiving ART in low-income and middle-income countries. The 11.7 million people on ART represent $36 \%$ of the 32.6 million people living with HIV in low-income and middle-income countries. ${ }^{1}$ 
The Southern Nations Nationalities and Peoples' Regional State is the third largest administrative region in Ethiopia and represents about $20 \%$ of the country's population. The prevalence of HIV in the region was estimated at $1.5 \%{ }^{2}$ According to the 2013 health performance report of the regional heath bureau, 35,271 patients had ever started on ART, while 24,900 patients were currently on ART, up from 14,493 in 2010 . $^{3}$

As the number of patients on ART continues to increase, it will be of paramount importance to give due focus to the quality of care, to ensure optimal viral suppression and to improve quality of life for people living with HIV/acquired immune deficiency syndrome. One of these is to ensure that patients are retained in care that will have both individual and societal benefit. ${ }^{4} \mathrm{~A}$ higher attrition rate has been linked to poorer viral suppression and increased morbidity and mortality, among many other undesirable outcomes, both at the community and individual level. ${ }^{5-11}$ Systematic reviews conducted previously indicate that rates of attrition from ART care are prevailing problems in sub-Saharan Africa. ${ }^{12-14}$ Previous studies in Ethiopia have shown a high attrition rate, although most were single facility-based studies and were conducted in relatively previous cohorts. ${ }^{9,15,16}$ Estimates of retention/attrition rates at the region level for relatively recent cohorts and comparisons of the rates in hospitals and health centers have not been done. Therefore, in this study, we estimated the attrition rate of HIV patients on ART in the region and attempted to identify predictors of such attrition, including facility type, which has not been studied previously. The findings will be used to identify interventions to improve retention in ART care.

\section{Materials and methods}

\section{Setting and HIV service delivery approach}

The study was conducted in the Southern Nations Nationalities and Peoples' Regional State, Ethiopia. In the region, there are 179 health facilities that are actively providing HIV-related services including ART. When disaggregated by facility type, there are 22 hospitals and 157 health centers. ${ }^{17}$ These facilities also provide a wide range of HIV prevention, treatment, care, and support services. HIV care in Ethiopia is delivered by a multidisciplinary team. The composition of the team depends on the facility type. The team normally consists of a clinician (medical doctor, nurse, or health officer), pharmacy personnel, and counselors for support with adherence. The team leader is a medical doctor if in the hospital setting or a health officer if in a health center. There is a formal referral and linkage system between hospitals and health centers. ${ }^{18,19}$

\section{Study design and population}

We collected data for the cohort of patients initiated on ART between July 2011 and August 2012 in 20 selected health facilities. Data collection ended in the last week of July, 2014. Considering the available resources, we selected 20 health facilities based on their share of the case load in the region.

Next, we prepared the sample universe for hospitals and health centers separately. In order to avoid too much travel for few card reviews, we decided to include only facilities with a total case load of more than 100 patients. Accordingly, 25 health centers and 22 hospitals were included in the sampling universe. Finally, a total of eight health centers and 12 hospitals were randomly selected, reflecting the fact that hospitals have higher patient loads than health centers. Random selection was done using a random number generator in Excel.

\section{Data collection procedure and data collectors}

A structured data abstraction format was used to extract the data from patient cards and corresponding registers. The format was developed using the standardized patient monitoring formats and registers employed by the ART clinics. Initially, ART registers were used to identify the cohort of interest. Then, using the unique ART number from the register, other patient data that were not available on the register were retrieved from other formats, ie, the patient follow-up form and the patient intake form. Some questions were also included to capture the characteristics of the facility.

The data collectors were already ART-trained health professionals who were actively working in ART care clinics in the region. They were trained for 3 days. The training sessions included the purpose of the research and pilot testing of the data collection tools and processes. The format and other technical features were amended as deemed necessary after pretesting. All members of the research team acted as supervisors during the entire data collection period.

\section{Data management and analysis}

Data were entered, cleaned, and analyzed using Statistical Package for the Social Sciences version 20.0 software (IBM Corporation, Armonk, NY, USA). Each questionnaire was given a unique identification number for entry to simplify data cleaning. Tables, graphs, and different statistical summary measures were calculated based on the nature of the variables and their distribution. The time-to-event method was used to investigate predictors of loss to follow-up (LTFU) 
or death after initiation of ART across independent variables. Because of the competing outcomes of death and LTFU, the cause-specific Cox models commonly used for time-to-event analysis would yield biased estimates. Therefore, the multivariate analysis and estimation of the cumulative incidence of LTFU and mortality were performed using competing risk regression models taking the other events of interest as the competing event. The data were entered into Statistical Package for the Social Sciences software, saved as Stata version $8 \mathrm{SE}$, and exported to Stata statistical software (Stata Corporation, Release 12, College Station, TX, USA). The regression analysis and cumulative incidence of LTFU or death was conducted using Stata version 12.0. We decided a priori to include selected variables in the multivariate model. Missing data for each factor was modeled as a separate category. For all statistical tests, the level of significance was set at a type I error of 0.05 .

\section{Definitions of terms used Loss to follow-up}

A patient was labeled as LTFU if he or she failed to visit the health facility for more than 3 months after the last appointment date. For the time-to-event analysis, the event date for LTFU was the last appointment date plus 91 days using the Gregorian calendar.

\section{Functional status}

Functional status was routinely assessed each time the patient came to the ART clinic for any purpose. A patient was categorized as "working" if their daily activities were not altered due to illness, "ambulatory" if the patient was not fully working but was able to do minor tasks at home, and "bed ridden" when the patient remained in bed most of the time.

\section{Ethical considerations}

Ethical clearance was obtained from the institutional review board of the Southern Nations Nationalities and Peoples' Regional State Health Bureau. In Ethiopia, patient consent is not required for use of data already existing within health facilities. The ethics statement from the regional health bureau waived the requirement for written consent from the study participants. Direct patient identifiers, like names, were not collected during the research. All the data obtained during the course of the study were held securely in hard and soft copy form in the computer files. Patient records were anonymized and deidentified prior to analysis. The data were analyzed as group data and not as individual data.

\section{Results}

\section{Facility characteristics}

The card reviews were conducted in 20 health facilities, comprising 12 hospitals and eight health centers. The selected facilities had a median HIV-related service of 8.0 (interquartile range [IQR] 7-8) years. The median years of service for the selected hospitals was 8 (IQR 7.25-8) years and for the selected health centers was 7.5 (IQR 6.25-8.0) years. In the 20 facilities studied, a total of 17,476 patients were currently actively on treatment at the time of data collection. The selected facilities had $70.2 \%$ of the total patient load in the region.

\section{Characteristics of study participants}

A total of 1,173 patients were included in the study. Their mean age was $33.7 \pm 9.6$ years. The majority were aged $26-39$ years. Around $40 \%$ of the patients were initiated on treatment in the same month as learning of their HIV infection status. More than half $(52.2 \%)$ did not have their height and/or weight recorded in any of the registers, so body mass index could not be calculated. Median CD4 count was 179 (IQR 93-263) cells $/ \mathrm{mm}^{3}$ at initiation of treatment. Around two-thirds of the hospital patients were included for chart review. Slightly more than half(53.6\%) were in the early WHO clinical stage, while $12.6 \%$ were diagnosed with tuberculosis at baseline. Other demographic and clinical characteristics are shown in Table 1.

\section{Follow-up duration and outcome}

A total of 2,356 person-years of observation (PYO) were available with a median follow-up duration until occurrence of any of the events or end of data collection time of 28 (IQR 22-31) months. The cumulative outcome was death, LTFU, or transfers out in $4.0 \%, 20.6 \%$, and $9.4 \%$, respectively. The remaining $66.0 \%$ were actively on treatment when data collection ended. When the analysis was performed separately for facility types, the cumulative incidence of death was $6.1 \%$ in health centers and $3.0 \%$ in hospitals, respectively, while the cumulative incidence of LTFU was $18.5 \%$ and $21.7 \%$ at health centers and hospitals. The incidence rate also showed a similar pattern. The death rate was 3.0 per 100 PYO in health centers and 1.5 per 100 PYO in hospitals. Figure 1 shows the overall incidence of the different outcomes and stratified by facility type.

\section{Cumulative incidence of death and LTFU stratified by facility type}

The cumulative incidence of death was higher in health centers than in hospitals while the cumulative incidence of 
Table I Baseline demographic and clinical characteristics of the study cohort, south Ethiopia

\begin{tabular}{|c|c|c|}
\hline Variable & $\mathbf{n}$ & $\%$ \\
\hline \multicolumn{3}{|l|}{ Sex } \\
\hline Male & 524 & 44.7 \\
\hline \multicolumn{3}{|c|}{ Gap between testing and treatment initiation } \\
\hline Same month & 468 & 39.9 \\
\hline I-6 months & 349 & 29.8 \\
\hline$>6$ months & 356 & 30.3 \\
\hline \multicolumn{3}{|l|}{ Marital status at enrolment $(n=|| 3 \mid)}$, \\
\hline Not married during enrolment & 478 & 40.8 \\
\hline Married at enrolment & 653 & 55.7 \\
\hline \multicolumn{3}{|l|}{ Family size $(n=I, 052)$} \\
\hline Living alone & 178 & 15.2 \\
\hline $2-5$ members & 734 & 62.6 \\
\hline$>5$ members & 140 & 11.9 \\
\hline \multicolumn{3}{|l|}{ Body mass index $(n=56 I)$} \\
\hline$<18.5$ & 181 & 15.4 \\
\hline$\geq 18.5$ & 380 & 32.4 \\
\hline \multicolumn{3}{|l|}{ Facility type } \\
\hline Hospital & 778 & 66.3 \\
\hline Health center & 395 & 33.7 \\
\hline \multicolumn{3}{|l|}{ CD4, cells $/ \mathrm{mm}^{3}(\mathrm{n}=\mathrm{I}, 082)$} \\
\hline$\leq 100$ & 293 & 25.0 \\
\hline$>100$ & 789 & 67.3 \\
\hline \multicolumn{3}{|l|}{ Age (years) at month 0} \\
\hline $15-25$ & 228 & 19.4 \\
\hline $26-39$ & 631 & 53.8 \\
\hline$\geq 40$ & 314 & 26.8 \\
\hline \multicolumn{3}{|l|}{ Isoniazid prophylaxis } \\
\hline Yes & 105 & 9.0 \\
\hline \multicolumn{3}{|l|}{ Cotrimoxazole prophylaxis } \\
\hline Yes & 1,085 & 92.5 \\
\hline \multicolumn{3}{|l|}{ Side effects } \\
\hline Yes & 42 & 3.6 \\
\hline \multicolumn{3}{|l|}{ Functional status $(\mathrm{n}=1,128)$} \\
\hline Working & 846 & 72.1 \\
\hline Ambulatory & 232 & 19.8 \\
\hline Bed ridden & 50 & 4.3 \\
\hline \multicolumn{3}{|l|}{ Disclosure $(\mathrm{n}=806)$} \\
\hline Disclosed & 763 & 65.1 \\
\hline Not disclosed & 43 & 3.7 \\
\hline \multicolumn{3}{|l|}{ Educational status $(\mathrm{n}=1,133)$} \\
\hline No education & 323 & 27.5 \\
\hline Primary education & 493 & 42.0 \\
\hline Secondary or higher & 317 & 27.0 \\
\hline \multicolumn{3}{|l|}{ TB treatment, month 0} \\
\hline Yes & 148 & 12.6 \\
\hline \multicolumn{3}{|l|}{ WHO clinical stage $(n=I, \mid 46)$} \\
\hline Early (stage I/II) & 629 & 53.6 \\
\hline
\end{tabular}

Abbreviations: TB, tuberculosis; WHO, World Health Organization.

LTFU was higher in hospitals than in health centers. Figure 2 shows the cumulative incidences of death and LTFU using competing risk analysis and stratified by facility type.

\section{Factors associated with LTFU and death}

Multivariate competing-risk regression analysis showed that longer time gap between knowing one's HIV infection status and treatment initiation, higher body mass index score at initiation of treatment, relatively older age, and secondary or higher educational status protected against LTFU. In contrast, not starting isoniazid preventive therapy, late WHO clinical stage, being in hospital-based care, and poor functional status at initiation of treatment increased the risk of LTFU from ART. Sex of the patient and other variables were not associated with LTFU from ART.

Moreover, analysis for the event of death showed that poor functional status at initiation of treatment, diagnosis of tuberculosis at treatment initiation, and being followed up in a health center rather than a hospital increased the risk of death in the study cohort. Although there is a decrease in the hazard of experiencing death as the CD4 increases, the association was not statistically significant. The other variables failed to reach statistical significance. Table 2 shows the multivariate Cox regression analysis results for LTFU and death.

\section{Discussion}

In this study, one quarter of patients were LTFU or had died after a median follow-up of 28 months. Another study conducted in two hospitals in the Oromia region, Ethiopia, documented a $10.3 \%$ death rate and an $18.0 \%$ LTFU rate over 2 years of follow-up. ${ }^{16}$ The higher death rate in the study from Oromia might be attributable to the fact that $85 \%$ of the study participants had a baseline CD 4 count $<200$ cells $/ \mathrm{mm}^{3}$, whereas this figure was $52.6 \%$ in our study. Similarly, $70.9 \%$ of the Oromia study participants were late-stage presenters, while in the current study only $44.1 \%$ presented late. Another study from south Ethiopia, in which the majority $(62.5 \%)$ of patients were late presenters, reported a death rate of $11.3 \% .{ }^{9}$ Such differences could be because of two reasons. First, patients may be presenting earlier in the course of the disease, and second, the shift in eligibility criteria to higher CD4 counts may also be contributing to early initiation of ART. This clearly indicates the public return in terms of lives saved because of early presentation and/or early treatment initiation for HIV.

Our attrition rate was higher than reports of $18 \%$ from rural Zimbabwe, ${ }^{20} 18 \%$ after 5 years of follow-up in Thailand, ${ }^{21} 16 \%$ after 2 years of follow-up in the People's Republic of China, ${ }^{22}$ and $10.7 \%$ after 2 years of follow-up in Rwanda. ${ }^{23}$ However, other studies have reported a comparable attrition rate. A study from rural Malawi reported an attrition rate of $23 \%{ }^{20}$ and another study from South Africa also reported an attrition rate of $26.4 \%$ among health facility based adherence support group, which is a similar context with our study. ${ }^{24}$ The current attrition rate is also similar to that in the 2003-2007 cohort in south Ethiopia. ${ }^{19}$ The sensitivity analysis of a systematic review conducted to estimate patient retention in 


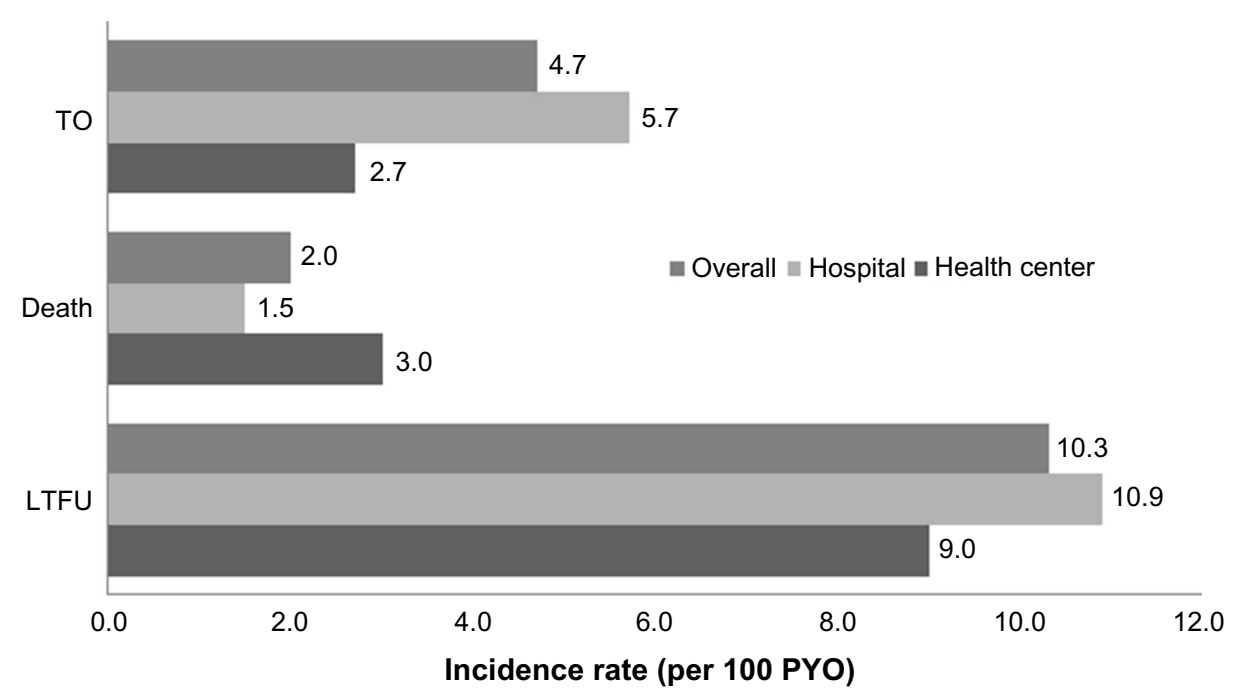

Figure I Overall incidence rates of LTFU and death stratified by facility type.

Abbreviations: LTFU, loss to follow-up; PYO, person-years of observation; TO, transfer out.

sub-Saharan Africa estimated that the retention rate ranged from $24 \%$ in the worst case to $77 \%$ in the best case at the end of 2 years of follow-up. ${ }^{12}$

Death rate calculations might be influenced by other external conditions. Health facilities may not accurately capture the death event. This implies that some patients classified as "lost" may have actually died if there is no strong tracing system to record the final outcome for such patients. In line with this, several studies have shown that most individuals who are LTFU have in fact died but are not detected by the health system. Previous studies conducted in south Ethiopia and Malawi have shown that around half of patients who are LTFU are found to be dead when traced by health facilities. ${ }^{9-11}$ Also, in the current study, the poor clinical condition, as measured in terms of WHO clinical stage, of patients who are LTFU suggests that these patients might have died of the disease, unbeknownst to the health system.

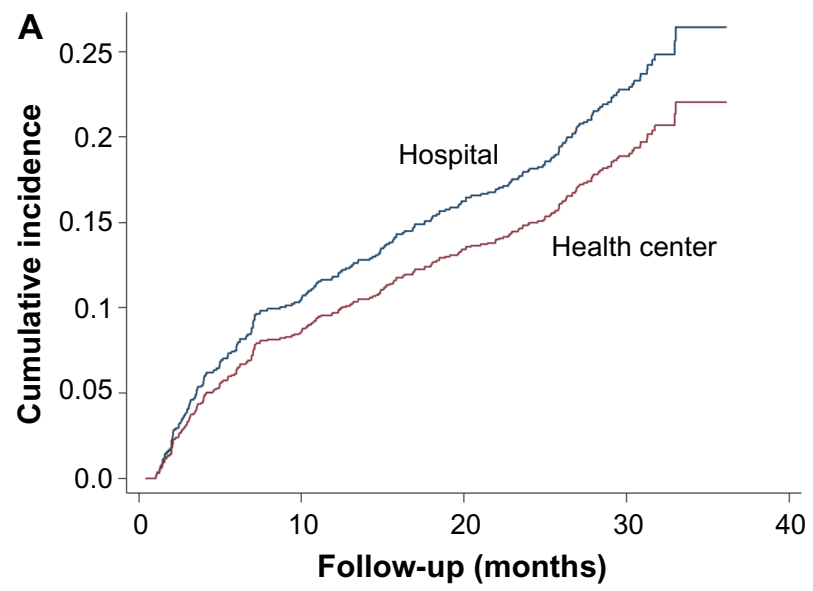

The overall death or LTFU rate of 12.4 per 100 PYO was much lower than that in a study from rural Malawi which reported attrition rates of 33 and 36 per 100 PYO in hospitals and health centers, respectively. ${ }^{25}$ This Malawi study also documented a significant reduction in incidence of LTFU and a higher death rate in health centers when compared with hospitals, similar to our findings. Higher death rates in health centers were also reported from other studies conducted in Malawi. ${ }^{20,25}$ In our study, we observed that patients who had a short time interval between learning of their HIV infection status and initiation of treatment were more likely to be LTFU when compared with their counterparts. This indicates that acceptance of disease status and long-term willingness to stay in care depends partly on to what level patients are psychologically accepting and managing the early denial stage of their HIV test result. Indepth counseling may be needed for patients

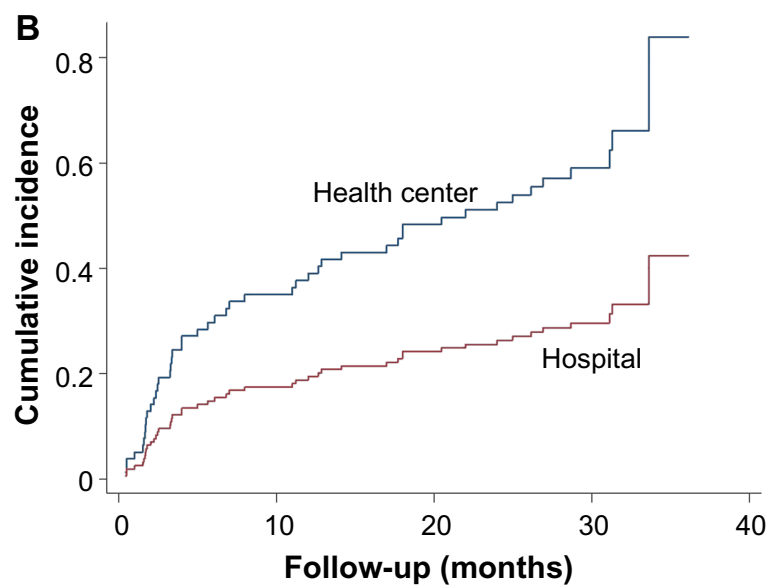

Figure 2 Cumulative incidence curves using competing risk analyses for LTFU (A) and death (B) by facility type. Abbreviation: LTFU, loss to follow-up. 
Table 2 Adjusted hazard ratios for LTFU and death using the competing-risk regression model, south Ethiopia

\begin{tabular}{|c|c|c|}
\hline Variable & $\begin{array}{l}\text { LTUF, AHR } \\
(95 \% \mathrm{CI})\end{array}$ & $\begin{array}{l}\text { Death, AHR } \\
(95 \% \mathrm{Cl})\end{array}$ \\
\hline \multicolumn{3}{|l|}{ Sex } \\
\hline Female versus male & $0.91(0.69-1.20)$ & $0.65(0.31-1.36)$ \\
\hline \multicolumn{3}{|c|}{ Gap between testing and treatment initiation } \\
\hline Same month & Reference category & Reference category \\
\hline $1-6$ months & $0.86(0.63-1.17)$ & $0.89(0.4 \mid-1.95)$ \\
\hline$>6$ months & $0.57(0.40-0.8 \mathrm{I})^{*}$ & $1.33(0.55-3.20)$ \\
\hline \multicolumn{3}{|c|}{ Marital status at enrolment } \\
\hline No during enrolment & Reference category & Reference category \\
\hline Married at enrolment & $0.8 I(0.6 I-I .12)$ & $0.73(0.34-1.55)$ \\
\hline $\mathrm{NR}$ & $0.65(0.29-1.44)$ & $1.91(0.40-9.09)$ \\
\hline \multicolumn{3}{|l|}{ Family size } \\
\hline Living alone & Reference category & Reference category \\
\hline $2-5$ & $0.80(0.55-1.17)$ & $0.70(0.3|-| .59)$ \\
\hline$>5$ members & $0.67(0.39-1.15)$ & $0.87(0.29-2.63)$ \\
\hline NR & $0.90(0.53-1.54)$ & $0.91(0.29-2.91)$ \\
\hline \multicolumn{3}{|l|}{ Body mass index } \\
\hline$<18.5$ & Reference category & Reference category \\
\hline$\geq 18.5$ & $0.58(0.38-0.91)^{*}$ & $0.71(0.23-2.17)$ \\
\hline$N R$ & $1.27(0.86-1.88)$ & $1.77(0.67-4.69)$ \\
\hline \multicolumn{3}{|l|}{ Facility type } \\
\hline $\mathrm{HC}$ versus hospital & $0.65(0.47-0.91)^{*}$ & $2.80(1.40-5.6 I)^{*}$ \\
\hline \multicolumn{3}{|l|}{$\mathrm{CD} 4$, cells $/ \mathrm{mm}^{3}$} \\
\hline$\leq 100$ & Reference category & Reference category \\
\hline$>100$ & $0.92(0.67-1.26)$ & $0.55(0.28-1.08)$ \\
\hline NR & $1.27(0.73-2.23)$ & $0.94(0.30-2.95)$ \\
\hline \multicolumn{3}{|l|}{ Age (years), at month 0} \\
\hline $15-25$ & Reference category & Reference category \\
\hline $26-39$ & $0.59(0.42-0.83)^{*}$ & $1.50(0.59-3.83)$ \\
\hline$\geq 40$ & $0.73(0.50-1.07)$ & $1.57(0.54-4.53)$ \\
\hline \multicolumn{3}{|l|}{ Isoniazid prophylaxis } \\
\hline No versus yes & $1.90(1.10-3.23)^{*}$ & $0.74(0.22-2.46)$ \\
\hline \multicolumn{3}{|c|}{ Cotrimoxazole prophylaxis } \\
\hline No versus yes & $1.07(0.64-1.79)$ & $1.44(0.36-5.80)$ \\
\hline \multicolumn{3}{|l|}{ Side effects } \\
\hline No versus yes & $0.82(0.44-1.54)$ & $0.50(0.19-1.34)$ \\
\hline \multicolumn{3}{|l|}{ Functional status } \\
\hline Working & Reference category & Reference category \\
\hline Ambulatory & $1.18(0.83-1.68)$ & $2.71(1.05-6.95)^{*}$ \\
\hline Bed ridden & $1.35(0.69-2.62)$ & $5.35(1.67-17.1)^{*}$ \\
\hline$N R$ & $1.71(0.77-3.76)$ & $1.75(0.33-9.16)$ \\
\hline \multicolumn{3}{|l|}{ Disclosure } \\
\hline Disclosed & Reference category & Reference \\
\hline Not disclosed & $1.67(0.85-3.28)$ & $0.30(0.03-3.17)$ \\
\hline Not documented & $0.96(0.70-1.31)$ & $1.36(0.65-3.87)$ \\
\hline \multicolumn{3}{|l|}{ Educational status } \\
\hline No education & Reference category & Reference category \\
\hline Primary education & $0.81(0.59-I . I I)$ & $0.60(0.28-I .3 I)$ \\
\hline Secondary or higher & $0.58(0.39-0.67)^{*}$ & $0.7 \mid(0.29-1.74)$ \\
\hline NR & $0.55(0.22-1.36)$ & $1.06(0.20-5.65)$ \\
\hline \multicolumn{3}{|l|}{ TB at baseline } \\
\hline No versus yes & $1.22(0.78-1.9 \mid)$ & $0.38(0.16-0.88)^{*}$ \\
\hline \multicolumn{3}{|l|}{ WHO stage } \\
\hline Late versus early & $1.39(1.03-1.88)^{*}$ & $0.85(0.38-1.88)$ \\
\hline
\end{tabular}

Note: *Statistically significant.

Abbreviations: AHR, adjusted hazard ratio; $\mathrm{Cl}$, confidence interval; $\mathrm{HC}$, health center; LTFU, loss to follow-up; NR, not recorded; TB, tuberculosis; WHO, World Health Organization. who start treatment relatively soon after learning of their HIV-positive status.

Other risk factors for an elevated risk of LTFU were low body mass index at treatment initiation, being in a young age group ( $\leq 25$ years), not starting isoniazid prophylaxis, being cared for in hospital rather than in a health center, not attending formal education, and late WHO clinical stage at initiation of treatment. Most of these findings are in agreement with those of several previous studies, ${ }^{9,10,15,22,23,26-32}$ Even though our point estimate for risk of LTFU or death showed males to be at increased risk, the association failed to reach statistical significance. However, other studies have found this relationship to be significant. ${ }^{22,26,28,31}$

The multivariate analysis showed that risk factors for death included being cared for in a health center rather than in a hospital, a diagnosis of tuberculosis at initiation of treatment, and poor functional status. These findings are similar to those of previous studies conducted in Ethiopia and elsewhere. ${ }^{9,16,27,28,31,33}$ The mortality excess is more than twice in health centers when compared with hospitals. This might be because of differences in the quality of care in terms of availability of facilities and high-level health workers to manage complicated cases. This calls for a careful analysis of the referral and linkage system in place to ensure an equitable distribution of health care services.

Finally, the study has some limitations inherent to the study design and the nature of the data collected. The findings are only for patients who were initiated on treatment and do not address retention over the continuum of HIV care. ${ }^{14}$ Missing values for some variables like body mass index were very large and may have resulted in bias or calculation errors. The possible outcomes might not have been accurately captured as patients who were classified as LTFU might have actually died or been cared for in other facilities. The competing-risk regression may partly solve the problem but the real final treatment outcome of the clients still remain

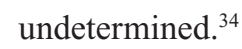

\section{Conclusion}

In this study, we noted that after a median follow-up of 28 months, one quarter of patients were either LTFU or had died. Compared with previous studies in similar settings, patients are now started on treatment at a relatively earlier stage. The LTFU rate was higher in hospitals than in health centers; however, there is an excess death rate among patients being followed up in health centers. We recommend further studies to explore why this is happening. 


\section{Acknowledgment}

The study was funded by the Federal HIV/AIDS Prevention and Control Office. We are grateful to the data collectors who extracted data from the registers, the data clerks in all the study facilities, and the heads of these health facilities.

\section{Disclosure}

The authors report no conflicts of interest in this work.

\section{References}

1. World Health Organization. HIV/AIDS. Available from: http://www. who.int/mediacentre/factsheets/fs360/en/. Accessed April 26, 2015.

2. Southern Nations, Nationalities and Peoples Regional State Health Bureau. Health Profile, 2011. Available from: http://www.snnprhb.gov. et/index.php?option=com_content $\&$ view $=$ article \&id=8\&Itemid=29.

3. AIDA Resource Center. ART Update as of end of Tir, 2002 (February 7 , 2010). Available from: http://www.etharc.org/index.php/resources/ download/view.download/42/347. Accessed April 26, 2015.

4. Stricker SM, Fox KA, Baggaley R, et al. Retention in care and adherence to ART are critical elements of HIV care interventions. AIDS Behav. 2013;18 Supp1 5:S459-S464.

5. Giordano TP. Retention in HIV care: what the clinician needs to know. Top Antivir Med. 19(1):12-16.

6. Crawford TN, Sanderson WT, Thornton A. Impact of poor retention in HIV medical care on time to viral load suppression. J Int Assoc Provid AIDS Care. 13(3):242-249.

7. Mugavero MJ, Lin H-Y, Willig JH, et al. Missed visits and mortality among patients establishing initial outpatient HIV treatment. Clin Infect Dis. 2009;48(2):248-256.

8. Giordano TP, Gifford AL, White AC, et al. Retention in care: a challenge to survival with HIV infection. Clin Infect Dis. 2007;44(11):1493-1499.

9. Mulissa Z, Jerene D, Lindtjørn B. Patients present earlier and survival has improved, but pre-ART attrition is high in a six-year HIV cohort data from Ethiopia. PLoS One. 2010;5(10):e13268.

10. Weigel R, Hochgesang M, Brinkhof MW, et al. Outcomes and associated risk factors of patients traced after being lost to follow-up from antiretroviral treatment in Lilongwe, Malawi. BMC Infect Dis. 2011;11:31.

11. Yu JK, Chen SC, Wang KY, et al. True outcomes for patients on antiretroviral therapy who are "lost to follow-up" in Malawi. Bull World Health Organ. 2007;85(7):550-554.

12. Rosen S, Fox MP, Gill CJ. Patient retention in antiretroviral therapy programs in sub-Saharan Africa: a systematic review. PLoS Med. 2007;4(10):e298.

13. Fox MP, Rosen S. Patient retention in antiretroviral therapy programs up to three years on treatment in sub-Saharan Africa, 2007-2009: systematic review. Trop Med Int Health. 2010;15 Suppl 1:1-15.

14. Mugglin C, Estill J, Wandeler G, et al. Loss to programme between HIV diagnosis and initiation of antiretroviral therapy in sub-Saharan Africa: systematic review and meta-analysis. Trop Med Int Health. 2012;17(12):1509-1520.

15. Berheto TM, Haile DB, Mohammed S. Predictors of loss to follow-up in patients living with HIV/AIDS after initiation of antiretroviral therapy. N Am J Med Sci. 2014;6(9):453-459.

16. Alemu AW, Sebastián MS. Determinants of survival in adult HIV patients on antiretroviral therapy in Oromiyaa, Ethiopia. Glob Health Action. 2010;3:5398.
17. RHB S. Annual performance review meeting of 2005 EFY. Arba Minch; 2013.

18. Federal Ministry of Health. Guidelines for antiretroviral treatment in Ethiopia. Addis Ababa, Ethiopia; 2008.

19. Seoum E, Mekonnen Y, Kassa A. et al. ART scale-up in Ethiopia. Successes and challenges. Available from: http://www.hapco.gov.et/index. php/resource-center/survery-and-research/file/66-art-scale-up-in-ethiopiasuccess-and-challenges?tmpl=component. Accessed April 27, 2015.

20. Rasschaert F, Koole O, Zachariah R, Lynen L, Manzi M, Van Damme W. Short and long term retention in antiretroviral care in health facilities in rural Malawi and Zimbabwe. BMC Health Serv Res. 2012;12:444.

21. Fregonese F, Collins IJ, Jourdain G, et al. Predictors of 5-year mortality in HIV-infected adults starting highly active antiretroviral therapy in Thailand. J Acquir Immune Defic Syndr. 2012;60(1):91-98.

22. Zhu H, Napravnik S, Eron J, et al. Attrition among human immunodeficiency virus (HIV)-infected patients initiating antiretroviral therapy in China, 2003-2010. PLoS One. 2012;7(6):e39414.

23. Mugisha V, Teasdale CA, Wang C, et al. Determinants of mortality and loss to follow-up among adults enrolled in HIV care services in Rwanda. PLoS One. 2014;9(1):e85774.

24. Fatti G, Meintjes G, Shea J, Eley B, Grimwood A. Improved survival and antiretroviral treatment outcomes in adults receiving communitybased adherence support: 5-year results from a multicentre cohort study in South Africa. J Acquir Immune Defic Syndr. 2012;61(4):e50-e58.

25. Massaquoi M, Zachariah R, Manzi M, et al. Patient retention and attrition on antiretroviral treatment at district level in rural Malawi. Trans $R$ Soc Trop Med Hyg. 2009;103(6):594-600.

26. Thai S, Koole O, Un P, et al. Five-year experience with scaling-up access to antiretroviral treatment in an HIV care programme in Cambodia. Trop Med Int Health. 2009;14(9):1048-1058.

27. Cuong DD, Thorson A, Sönnerborg A, et al. Survival and causes of death among HIV-infected patients starting antiretroviral therapy in north-eastern Vietnam. Scand J Infect Dis. 2012;44(3):201-208.

28. Alvarez-Uria G, Naik PK, Pakam R, Midde M. Factors associated with attrition, mortality, and loss to follow up after antiretroviral therapy initiation: data from an HIV cohort study in India. Glob Health Action. $2013 ; 6: 21682$

29. Farahani M, Vable A, Lebelonyane R, et al. Outcomes of the Botswana national HIV/AIDS treatment programme from 2002 to 2010: a longitudinal analysis. Lancet Glob Health. 2014;2(1):e44-e50.

30. Huang D, Zheng W, Yang J, Li Y, Hu A, Xu Z. [Study on the prevalence of loss to follow-up and risk factors among human immunodeficiency virus (HIV)/acquired immunodeficiency syndrome (AIDS) patients in Baoshan city, Yunnan province]. Zhonghua Yu Fang Yi Xue Za Zhi. 2014;48(8):688-692. Chinese.

31. Somi G, Keogh SC, Todd J, et al. Low mortality risk but high loss to follow-up among patients in the Tanzanian national HIV care and treatment programme. Trop Med Int Health. 2012;17(4):497-506.

32. Thida A, Tun ST, Zaw SK, et al. Retention and risk factors for attrition in a large public health ART program in Myanmar: a retrospective cohort analysis. PLoS One. 2014;9(9):e108615.

33. Sieleunou I, Souleymanou M, Schönenberger A-M, Menten J, Boelaert M. Determinants of survival in AIDS patients on antiretroviral therapy in a rural centre in the Far-North Province, Cameroon. Trop Med Int Health. 2009;14(1):36-43.

34. McMahon JH, Elliott JH, Hong SY, Bertagnolio S, Jordan MR. Effects of physical tracing on estimates of loss to follow-up, mortality and retention in low and middle income country antiretroviral therapy programs: a systematic review. PLoS One. 2013;8(2):e56047. 
HIV/AIDS - Research and Palliative Care

\section{Dovepress}

\section{Publish your work in this journal}

HIV/AIDS - Research and Palliative Care is an international, peerreviewed open-access journal focusing on advances in research in HIV, its clinical progression and management options including antiviral treatment, palliative care and public healthcare policies to control viral spread. The journal welcomes original research, basic science,

clinical \& epidemiological studies, reviews \& evaluations, expert opinion \& commentary, case reports \& extended reports. The manuscript management system is completely online and includes a very quick and fair peer-review system. Visit http://www.dovepress.com/ testimonials.php to read real quotes from published authors.

Submit your manuscript here: http://www.dovepress.com/hivaids---research-and-palliative-care-journal 